\title{
Immunologic and Clinical Investigation on a Bovine Thymic Extract. Therapeutic Applications in Primary Immunodeficiencies
}

\author{
F. AIUTI, P. AMMIRATI, M. FIORILl, R. D'AMELIO, F. FRANCHI, M. CALVANI, AND L. BUSINCO \\ Department of Internal Medicine III, University of Rome (F. A., P. A., M. F., R. D., F. F.) and Department of \\ Pediatrics, University of Rome, (M. C., L. B.) Rome, Italy
}

\section{Summary}

Thirteen patients with primary immunodeficiencies (eight with T-cell deficiency, one with Wiskott-Aldrich (W-A) syndrome, two with common variable agammaglobulinemia (CVA), and two with severe combined immunodeficiency (SCID)) were treated with a calf thymus extract, called thymostimulin (TS). It has been shown that this extract causes in vitro differentiation of $\mathrm{T}$-cell precursors in patients with $\mathbf{T}$-cell defect. Five of eight patients with pure $\mathbf{T}$ cell defect showed immunologic recovery and clinical remission lasting for several months after interruption of the therapy; one had only transient reconstitution, one had slight increase in $T$ cells (clinical conditions not yet estimated), and two patients soon died from severe infections after showing a slight increase of $T$ cells.

Immune recovery was assessed by an increase of the absolute number of E-rosettes forming cells, of human T-lymphocyte antigen positive cells and of PHA responsiveness in the peripheral blood, and by a positive delayed hypersensitivity reaction to antigens. In five patients, there was also B-cell increase after TS treatment. Clinical remission consisted of disappearance of infections, weight gain, and in improvement in general conditions.

No effect was observed in one patient with W-A syndrome, in two with CVA, and in two with SCID. Several hypotheses on the mechanisms involved in immune reconstitution are discussed. It seems likely that TS acts on prethymic cells or on the epithelial cells of hypoplastic thymuses. TS was not effective, either in vitro or in vivo, in patients with SCID probably because of a defect in stem cells.

\section{Speculation}

Thymic hormone therapy can be valid only in same patients with T-cell defect, after in vitro assessment of $T$-cell differentiation. Further experiments will be necessary to establish if this therapy can be extended in other deficiencies of cell mediated immunity associated to infections, malignancies, autoimmune syndromes, and malnutrition.

Previous in vitro and in vivo experiments have shown that animal and human thymic factors are capable of inducing or increasing T-cell markers and T-cell functions and of enhancing body defenses against infections, autoimmune diseases, and neoplasia. These data were summarized in Part 1 of this paper (7) and in recent editorials on thymic hormones $(4,5,9)$.

Preliminary trials with calf thymic extract treatment of patients with primary or secondary immunodeficiencies will induce partial or full restoration of T-cell defects $(1,2,8,17,19)$. The data reported were obtained from a limited number of patients with different diseases, and did not include in vitro studies and longterm controls after treatment.
In Part 1 of this paper we reported that a calf thymic factor, called TS, is capable of inducing in vitro $\mathrm{T}$-cell differentiation in patients with T-cell defects, while in other immunodeficiencies, it was ineffective (7). In this paper, the clinical and immunologic studies observed after TS treatment in immunodeficient patients are described. Our results suggest that TS can be a useful therapeutic approach for some patients with $\mathrm{T}$-cell defects while it seems ineffective in other immunodeficiencies.

\section{MATERIALS AND METHODS}

The detection of membrane IgG, IgA, and IgM on lymphocytes by immunofluorescence was carried out according to the method of Pernis et al. (15), with commercial antisera. The results of total Ig binding cell counts are reported in percent values. In vitro response of lymphocytes to PHA (Wellcome) was assessed by the incorporation of $3 \mathrm{H}$-thymidine, and the stimulatory index mean values of three samples is reported.

Delayed hypersensitivity skin tests were performed with streptokinase-streptodornase (SK-SD) $40 \mathrm{U}$. (Lederle), Candida 1:10 (Hollister-Stier), and PHA $1 \mu \mathrm{g}$ (Wellcome). The skin tests were considered positive if the induration area was more than $5 \mathrm{~mm}$. The concentration of serum immunoglobulins was determined by the method of Mancini et al. (13). The other immunologic tests were performed as described in Part 1 of this paper (7). They include E-rosettes, cytotoxicity with anti-T serum with and without TS incubation. The baseline and in vitro incubation with TS test was carried out on different days from routine E-rosette test. For this reason, there are slight differences between the two findings. The E-rosette test and human $T$ lymphocyte antigen (HTLA) before treatment with TS were repeated in all patients at least three times; the mean values of several observations were reported. In all cases checked, erythrocytes, adenosine deaminase, and nucleosidephosphorylase levels were normal. In cases 4,8 , and 12 the enzymes were not studied. The TS used in our trials was the same employed in in vitro experiments. This TS was capable of inducing mouse spleen lymphocytes reactivity to mitogen stimulation and of stimulating immature lymphoid cells to induce an in vivo graft-versus-host reaction in mice (6). The extract did not cause any toxic effect when administered to mice in doses of up to $100 \mathrm{mg} / \mathrm{kg}$ and did not alter the neuromuscular transmission.

As a general schedule, TS was administered in a single 7-day course of $1 \mathrm{mg} / \mathrm{kg} /$ day intramuscularly, followed by maintenance doses given weekly or twice a week. Different schedules of administration are referred in case reports.

\section{CASE REPORTS AND RESULTS}

We treated eight patients with T-cell defects and severe infections, two with SCID and cytomegalovirus infection (CMV), one 
with CVA and one with W-A syndrome. The diagnosis was based on clinical criteria and laboratory data. Transfer factor prepared in our laboratories from a Candida positive donor was administered to one patient in addition to TS. Before TS administration, all children were treated unsuccessfully with antibiotics or antifungal agents for several weeks.

Despite TS therapy, five patients died due to severe infections or hemorrhages and the postmortem examination confirmed the diagnosis of immunodeficient patients. These findings confirmed the extremely critical conditions of our patients undergoing thymic extract therapy.

Case 1. R. R., 1-month-old male, diagnosis: T-lymphocyte defect. From birth, the infant suffered from generalized mucocutaneous candidiasis and recurrent upper and lower respiratory tract infections. At the age of $\mathbf{4 5}$ days, due to the extremely critical clinical conditions and the severe lymphopenia, TS therapy was initiated. Two weeks later, the severity and frequency of the infections decreased, a marked weight gain was observed and the general conditions improved. TS treatment was continued at the same dose twice a week for 3 months. At present, 1 yr since therapy was interrupted, the child is doing well and is free of infections. The T-lymphocyte defect has been corrected (Tables 1 , 2).

Case 2. C. A., 4-month-old female, diagnosis: T-lymphocyte. Failure to thrive and chronic diarrhea were present from the first month of life. At 4 months of age, the patient developed meningitis, sepsis, and pneumonia. Due to the severe clinical conditions and T-lymphocytes defect, TS therapy was begun at 7 months of age. After 1 week, the clinical condition improved and T-lymphocytes also increased (Tables 1, 2). At this point, therapy was temporarily discontinued for lack of available TS. After a 2-week suspension, the clinical condition worsened, pulmonary infections reappeared, and T-lymphocytes decreased (Tables 1,2 ). Therapy was then resumed and continued twice a week for two months. At the present time (1 year later), the general conditions are satisfactory.

Case 3. L. M., 1-month-old male, diagnosis: T-lymphocyte defect and Trisomy 21 . The infant suffered from recurrent respiratory tract infections, otitis media, and mucocutaneous candidiasis. After 1 week of TS therapy, there was a marked clinical improvement, regression of infections, and weight gain. Despite TS treatment for 2 months, the infections reappeared and Erosettes decreased. Daily administration of TS was begun, E-RFC normalized, but there was no clinical improvement. At 6 months of age, the infant died of bronchopneumonia. Postmortem examination revealed thymic aplasia and severe depletion of lymphocytes in T-dependent areas of lymphnodes.

Case 4. C. C., 1-month-old female, diagnosis: T-lymphocyte defect and CMV. From the second week of life, the infant had been hospitalized for acute respiratory infection. On admission, her temperature was $39.5^{\circ} \mathrm{C}$, there was severe respiratory distress, with clinical and radiologic evidence of diffuse, bilateral interstitial pneumonia. At X-ray examination, the thymic shadow was very reduced. The liver and spleen were palpable, respectively, 4 and $3 \mathrm{~cm}$ below the costal margin. The CMV was isolated repeatedly from urine. The serum immunoglobulins and total blood count were normal. However, severe lymphopenia (12\%) and low T-cells and depression of mitogenic response were observed. CMV antibodies in her serum were $<: 8$ (complement fixation) at 1 month of life, but became positive after 2 months. TS was administered at the end of the first month at a dose of $1 \mathrm{mg} / \mathrm{kg} / \mathrm{day}$ intramuscularly. Within 5 days, a dramatic clinical improvement was observed, manifested by the appearance of normalization of breathing and oxygenation of the blood. Two days later, the temperature fell to normal. Two weeks later, the X-rays normalized and the reevaluation of cellular immunity revealed an increase in the absolute and percent number of $\mathrm{T}$-cells and was maintained in four additional examinations made during the next 10 months. The CMV in the urine became negative after 3 months.

Case 5. A. A., 7-yr-old male, diagnosis: T-lymphocyte defect. From birth, the patient suffered from diarrhea, severe asthma, and recurrent mucocutaneous infections. Immunologic studies performed over a period of 2 months are reported in Tables 1, 2, 3 . After 10 days of TS treatment, a regression of the herpes infection

Table 1. E-rosettes in patients with T-lymphocyte defect before and after TS therapy

\begin{tabular}{|c|c|c|c|c|c|c|c|c|c|c|}
\hline \multirow[b]{2}{*}{ Patient } & \multirow[b]{2}{*}{ Age } & \multirow[b]{2}{*}{ Test } & \multirow[b]{2}{*}{ Before' } & \multicolumn{6}{|c|}{ After ${ }^{2}$} & \multirow[b]{2}{*}{ Comment } \\
\hline & & & & 1 & 2 & 4 & 8 & 12 & $24-56$ & \\
\hline \multirow[t]{2}{*}{ 1. R. R. } & 1 month & $\mathrm{E} \%$ & $12-19$ & 40 & 47 & 66 & 35 & 28 & 56 & Clinical improvement \\
\hline & & $\mathrm{E} / \mathrm{mm}^{3}$ & $180-240$ & 1970 & 2200 & 2600 & 440 & 420 & 1680 & \\
\hline \multirow[t]{2}{*}{ 2. C. A. } & 4 months & $\mathrm{E} \%$ & $12-18$ & 60 & $\mathrm{ND}^{3}$ & 7 & 60 & 70 & 68 & Clinical improvement \\
\hline & & $\mathrm{E} / \mathrm{mm}^{3}$ & $340-460$ & 1900 & $\mathrm{ND}^{3}$ & 320 & 2100 & 1870 & 2200 & \\
\hline \multirow[t]{2}{*}{ 3. L. M. } & 1 month & $\mathrm{E} \%$ & $20-28$ & 48 & 47 & 51 & 29 & 61 & & Dead \\
\hline & & $\mathrm{E} / \mathrm{mm}^{3}$ & $200-240$ & 1240 & 750 & 1630 & 1450 & 2440 & & - \\
\hline \multirow{3}{*}{ 4. C. C. } & imonth & & & & & & & & & \\
\hline & 1 month & $\begin{array}{l}\mathrm{E} \% \\
\mathrm{E} / \mathrm{mm}^{3}\end{array}$ & $10-24$ & 50 & $\mathrm{ND}^{3}$ & $\begin{array}{r}18 \\
260\end{array}$ & $\begin{array}{r}43 \\
2720\end{array}$ & $\begin{array}{r}69 \\
2300\end{array}$ & 64 & Clinical improvement \\
\hline & & & $200=900$ & & & & 1720 & 2300 & & - \\
\hline \multirow[t]{2}{*}{ 5. A. A. } & $7 \mathrm{yr}$ & $\mathrm{E} \%$ & $18-32$ & 45 & 28 & 18 & 65 & 38 & $\mathrm{ND}^{3}$ & Transitory clinical improve- \\
\hline & & $\mathrm{E} / \mathrm{mm}^{3}$ & $250-430$ & 1210 & 800 & 500 & 1100 & 500 & $\mathrm{ND}^{3}$ & ment \\
\hline \multirow[t]{2}{*}{ 6. M. G. } & $1 \mathrm{yr}$ & E \% & $10-20$ & 47 & $\mathrm{ND}^{3}$ & 51 & & & & Dead \\
\hline & & $\mathrm{E} / \mathrm{mm}^{3}$ & $120-200$ & 520 & $\mathrm{ND}^{3}$ & 1220 & & & & \\
\hline \multirow[t]{2}{*}{ 7. F. D. } & 8 months & $\mathrm{E} \%$ & $7-19$ & 35 & $\mathrm{ND}^{3}$ & 62 & 57 & 70 & 68 & Clinical improvement \\
\hline & & $\mathrm{E} / \mathrm{mm}^{3}$ & $140-170$ & 870 & $\mathrm{ND}^{3}$ & 2170 & 2850 & 3500 & 3200 & \\
\hline \multirow[t]{2}{*}{ 8. P. G. } & 5 yr & $\mathrm{E} \%$ & $0-10$ & 24 & 30 & 30 & 20 & 20 & 38 & Clinical improvement \\
\hline & & $\mathrm{E} / \mathrm{mm}^{3}$ & $0-54$ & 166 & 240 & 132 & 128 & $\mathrm{ND}^{3}$ & 840 & \\
\hline
\end{tabular}

\footnotetext{
${ }^{1}$ Maximum and minimal values of $\mathrm{E} \%$ and $\mathrm{E} / \mathrm{mm}^{3}$ during the period of observation (from 2 wk to 2 months) before treatment.

${ }^{2}$ Weeks after the onset of TS treatment.

${ }^{3} \mathrm{ND}=$ not done.
} 
Table 2. HTLA and skin tests in patients wtih T-lymphocyte defect before and after TS therapy

\begin{tabular}{|c|c|c|c|c|c|c|}
\hline Patient & Test $^{1,2}$ & Before & \multicolumn{3}{|c|}{ After $^{3}$} & Comment \\
\hline 1. R. R. & $\begin{array}{l}\text { HTLA } \\
\text { ST }\end{array}$ & $\begin{array}{l}15 \\
\text { PHA+ }\end{array}$ & $\begin{array}{l}\mathrm{ND}^{4} \\
\mathrm{ND}^{4}\end{array}$ & $\begin{array}{l}44 \\
\text { Positive }\end{array}$ & $\begin{array}{l}\mathrm{ND}^{4} \\
\text { Positive }\end{array}$ & Clinical improvement \\
\hline 2. C. A. & $\begin{array}{l}\text { HTLA } \\
\text { ST }\end{array}$ & $\begin{array}{l}11 \\
\text { Negative }\end{array}$ & $\begin{array}{l}34 \\
\mathrm{ND}^{4}\end{array}$ & $\begin{array}{l}\mathrm{ND}^{4} \\
\mathrm{ND}^{4}\end{array}$ & $\begin{array}{l}70 \\
\text { Positive }\end{array}$ & Clinical improvement \\
\hline 4. C. C. & $\begin{array}{l}\text { HTLA } \\
\text { ST }\end{array}$ & $\begin{array}{l}12 \\
\text { Negative }\end{array}$ & $\begin{array}{l}34 \\
\mathrm{ND}^{4}\end{array}$ & $\begin{array}{l}55 \\
\mathrm{ND}^{4}\end{array}$ & $\begin{array}{l}60 \\
\text { Positive }\end{array}$ & Clinical improvement \\
\hline 5. A. A. & $\begin{array}{l}\text { HTLA } \\
\text { ST }\end{array}$ & $\begin{array}{l}\mathrm{ND}^{4} \\
\mathrm{ND}^{4}\end{array}$ & $\begin{array}{l}\mathrm{ND}^{4} \\
\mathrm{ND}^{4}\end{array}$ & $\begin{array}{l}\text { ND }^{4} \\
\text { Positive }\end{array}$ & Positive & Transitory clinical improvement \\
\hline 7. F. D. & $\begin{array}{l}\text { HTLA } \\
\text { ST }\end{array}$ & $\begin{array}{l}\mathrm{ND}^{4} \\
\text { Negative }\end{array}$ & $\begin{array}{l}\mathrm{ND}^{4} \\
\text { Negative }\end{array}$ & $\begin{array}{l}\text { ND }^{4} \\
\text { Positive }\end{array}$ & $\begin{array}{l}\text { ND }^{4} \\
\text { Positive }\end{array}$ & Clinical improvement \\
\hline 8. P. G. & $\begin{array}{l}\text { HTLA } \\
\text { ST }\end{array}$ & $\begin{array}{l}40 \\
\text { Negative }\end{array}$ & $\mathrm{ND}^{4}$ & 48 & $\begin{array}{l}\mathrm{ND}^{4} \\
\text { Positive }\end{array}$ & Clinical improvement \\
\hline
\end{tabular}

'HTLA: Human T-lymphocyte antigen positive cells reported in percent.

${ }^{2}$ ST: Skin tests: Candida, PHA and SK-SD (when not specified all skin tests converted to positive).

${ }^{3}$ Weeks after treatment.

${ }^{4}$ ND: Not done.

was observed and lymphocytes increased. Treatment was continued twice a week for 2 months. During this time T-lymphocytes decreased. For this reason, TS was administered daily for 1 week and E-RFC normalized. Furthermore, Candida, SK-SD, PHA, and herpes skin tests converted. Four months after suspension of TS, the herpes infection reappeared with a decrease of T-lymphocytes.

Case 6. M. G., 1-yr-old male, diagnosis: T-lymphocyte defect and cerebral malformation. This infant, with cerebral malformation, suffered from recurrent respiratory infections and failure to thrive from birth. Immunologic data are reported in Tables 1, 2, 3. Treatment with TS was attempted, and despite the improvement of immunologic tests, the severe clinical condition persisted and the patient died from pneumonia after 1 month. Autopsy revealed thymic aplasia, lymph node depletion in the T-dependent areas, and pneumonia from pneumocystis carinii.

Case 7. F. D., 8-month-old male, diagnosis: T-lymphocyte defect and heart malformation. From the first month of life, severe diarrhea, pneumonia, and thrush were present. TS therapy was administered according to the routine schedule for 3 months. Tables 1, 2, 3 show the immunologic improvement. The clinical conditions gradually normalized and, at present, 1 year after the suspension of therapy, the child is in good condition. Three months ago, his heart malformation was corrected. During surgery, his thymus appeared normal.

Case 8. P. G., 4-yr-old male, diagnosis: recurrent infections, defect of phagocytosis, and T-lymphocyte defect. From 7 months of age, the patient suffered from recurrent upper and lower respiratory infections. At $1 \mathrm{yr}$, he developed severe, generalized reaction to smallpox vaccine. After tetanus-diphtheria vaccine, he developed chronic infiltration of the gluteus muscles and, subsequently, chronic abscesses of mouth and lymph nodes. The abscesses had little tendency to suppuration. Gram-negative bacteria were isolated from the blood. The NBT test was normal, defect of phagocytosis of latex particles and candida were documented, while chemotaxis was increased. The E-rosettes were always lower than $12 \%$ and $\mathrm{T} / \mathrm{mm}^{3}$ less than $400(80-378)$. After TS, the T- lymphocytes increased, but after 2 months of therapy, no improvement was observed in clinical symptoms (Table 1). However, after 1 year of treatment, a marked clinical improvement was observed.

Case 9. M. C., 6-month-old female, diagnosis: SCID. From the first weeks of life, the infant suffered from recurrent pneumonia, intractable diarrhea, thrush, and failure to thrive. Immunologic tests confirmed the diagnosis of SCID and CMV infection was revealed. Due to the absence of HLA, identical bone marrow donor, transfer factor was administered without clinical or immunologic benefit. Despite 2 weeks of TS treatment, no immunologic or clinical improvement was obtained. The patient died from severe pneumonia. Postmortem examination showed thymic aplasia and severe generalized depletion of the lymphoid system.

Case 10. F. S., 3-month-old male, diagnosis: SCID. One brother died from SCID. From the second week of life, the infant suffered from interstitial pneumonia and diarrhea. CMV was detected in the urine. The antibodies against respiratory viruses were negative. The absence of E-RFC, PHA response, natural and immune antibodies confirmed the diagnosis of SCID. The incubation of lymphocytes with TS did not improve the number of E-RFC nor HTLA positive cells (not reported in Part 1). The administration of TS was performed for 2 weeks without clinical or immunologic improvement.

Case 11. C. T., 8-yr-old male, diagnosis: CVA. From $4 \mathrm{yr}$ of age, the boy suffered from autoimmune hemolytic anemia and severe respiratory tract infections. A deficiency of $\mathrm{IgG}$ and an absence of IgA were present, the E-RFC were normal. Because the PHA response was depressed and the skin tests were negative, TS therapy was begun. After 3 weeks of therapy, a normalization of the PHA was observed; the stimulation index rose from 5 to 33 . After 2 months of therapy, an enlargement of the paraileal lymph nodes appeared and the treatment was interrupted. At present (1 yr later), the patient is in fair health, however, $\operatorname{IgA}$ and IgG deficiencies still persist while the E-RFC and PHA responses are normal.

Case 12. M. E., 5-yr-old female, diagnosis: CVA (IgG, IgA deficiency). The girl suffered from severe respiratory tract infec- 
tions and chronic diarrhea. Secretory and serum IgA were absent, the E-RFC were decreased, and PHA response was depressed. The in vitro response to TS was negative. The therapy modified neither the clinical symptoms nor the immunodeficiency. The patient died at home of bronchopneumonia.

Case 13. L. R., 2-yr-old male, diagnosis: W-A syndrome. From birth, the patient suffered from repeated pneumonia, mucocutaneous candidiasis, intractable diarrhea, and exzema. From the age of $1 \mathrm{yr}$, he had also been affected intermittently with melena and hematomesis. Platelets varied from 10,000-20,000. T-cells were depressed (E-RFC $25 \%$ and $335 \mathrm{~mm}^{3}$ ), there was a depressed response to $\mathrm{PHA}$, and the skin tests were negative. The in vitro incubation test with TS was not significant $(+5 \%)$. After TS therapy, a normalization of the PHA response and T-cell number were observed. The skin tests remained negative. Three weeks after discharge, the child died suddenly at home from severe gut bleeding.

In all patients treated with TS, no local or general side effects were observed, and the liver and kidney functional tests were normal during and after the therapy. The immunologic data of patients with T-cell deficit before and after therapy with TS are summarized in Tables 1,2 , and 3 . The in vitro incubation with TS induced significant increase of E-RFC and/or HTLA in all patients with T-defect. In four of eight patients. with T-lymphocyte defects, TS induced long-term clinical improvement and correction of the immunologic disorder (Table 1 and Fig. 1).

Only differences greater than $8 \%$ and $370 \mathrm{~T}$-cell $/ \mathrm{mm}^{3}$ above or below baseline should be considered treatment-dependent, because six normal controls (aged 3 months- 3 yr) who did not undergo thymic extract therapy showed spontaneous variation of $\mathrm{T}$-cells in this order of magnitude (Ciarla et al., unpublished

Table 3. PHA response in patients with T-lymphocyte defect before and after TS therapy

\begin{tabular}{|c|c|c|c|c|}
\hline \multirow[b]{2}{*}{ Patient } & \multirow[b]{2}{*}{ Before $^{1}$} & \multicolumn{3}{|c|}{ After $^{2}$} \\
\hline & & 1. & 12. & $24-70$ \\
\hline \multirow[t]{2}{*}{ 1. R. R. } & $230 / 690$ & & $345 / 21735$ & $412 / 36256$ \\
\hline & $\begin{array}{l}\text { cpm/min } \\
\text { SI } 3\end{array}$ & $\mathrm{ND}^{3}$ & 63 & 88 \\
\hline \multirow[t]{2}{*}{ 2. C. A. } & $255 / 1275$ & $\mathrm{ND}^{3}$ & $412 / 11536$ & $317 / 17752$ \\
\hline & 5 & & 28 & 56 \\
\hline \multirow[t]{2}{*}{ 3. L. M. } & $540 / 1620$ & $302 / 2416$ & & \\
\hline & 3 & 8 & ND & \\
\hline \multirow[t]{2}{*}{ 4. C. C. } & $506 / 584$ & & $246 / 18436$ & $389 / 9336$ \\
\hline & 2 & $\mathrm{ND}^{3}$ & 6 & 24 \\
\hline \multirow[t]{2}{*}{ 5. A. A. } & $580 / 1160$ & & $544 / 18436$ & \\
\hline & 2 & $\mathrm{ND}^{3}$ & 34 & $\mathrm{ND}^{3}$. \\
\hline \multirow[t]{2}{*}{ 6. M. G. } & $212 / 436$ & & & \\
\hline & 2 & $N^{3}$ & & \\
\hline \multirow[t]{2}{*}{ 7. F. D. } & $345 / 690$ & $463 / 13890$ & $502 / 22088$ & $531 / 27612$ \\
\hline & 2 & 30 & 44 & 52 \\
\hline \multirow[t]{2}{*}{ 8. P. G. } & $416 / 475$ & $385 / 2310$ & $406 / 3248$ & $489 / 7824$ \\
\hline & 1 & 6 & 8 & 16 \\
\hline
\end{tabular}

\footnotetext{
'The results are expressed both in cpm counts per minute of tritiated thymidine incorporated by microcultures (first line) of baseline and stimulated samples. The stimulating index (S.I.) (ratio of nonstimulated/ stimulated culture) is reported in the second line. The normal mean values (results from 9 values) are the following: mean; $285 \pm: 112$ (nonstimulation) and $26700 \pm 9000$ (after stimulation).

${ }^{2}$ Weeks after treatment.

${ }^{3} \mathrm{ND}$ : not done.
}

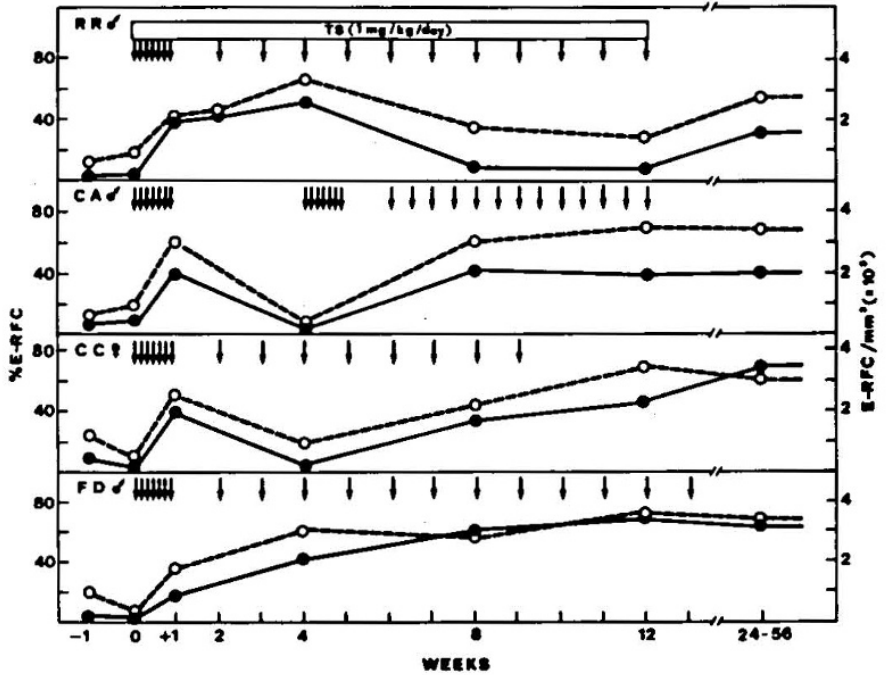

Fig. 1. Percent number (-) and absolute number $(-)$ of E-RFC in peripheral blood of patients with T-cell defect treated with the thymic extract TS $(\downarrow)$.

experiments). These controls were followed for 3 months and showed a variation of $8 \%$ above or below the baseline. In all four patients checked for HTLA, positive cells increased after TS (Table 2). PHA response normalized in six of eight patients, good correlation between $\mathrm{T}$-cell number and mitogenic response was observed, and both agreed with the clinical condition (Table 3). Skin tests were also reported in Table 2 and became positive after therapy in four of eight patients. The delayed hypersensitivity reaction appeared later in comparison to other immunologic tests, but skin response to PHA and SK-SD was persistently negative in case 4. An increase in B-cell absolute count was observed in six of eight patients, while the percent of surface membrane immunoglobulins lymphocytes remained without variation (Table 4). No significant modifications occurred in Ig levels.

None of the recipients presented any signs of immediate hypersensitivity reaction after TS injection. In addition, in five patients, the antibodies against TS and bovine proteins were checked both by immunodiffusion and hemoagglutination techniques. The results were all negative. On the contrary, in two rabbits immunized with TS and Freund adjuvant, after 1 month from the first immunization, antibodies of IgG type developed. No antibodies were detected against serum bovine proteins by immunoelectrophoresis (Ammirati and Aita, in preparation).

\section{DISCUSSION}

Preliminary in vitro and in vivo experiments of other investigators have brought to light the activity of thymic extracts and the role of T-dependent lymphoid cell differentiation in the defense mechanisms against infections and tumors $(8,9,18,19)$.

It was recently demonstrated that thymosin (A. L. Goldstein, fraction 3) is capable of restoring the response to PHA and the function of killer and helper cells, and of enhancing the rejection of methylcholanthrene induced fibrosarcoma in nude mice (14). Control nude mice treated with splenic extract did not show Tcell function, nor rejected tumor cells.

Goldstein's fraction 5 thymosin has been used with fair clinical and immunologic success in subjects with primary immunodeficiency $(8,9,11,16,19)$ and in immunodeficiencies associated with Hodgkin's disease, systemic lupus erythematosus, and lymphoproliferative disorders $(2,8,9,17)$. The most evident effect in these patients was an increase in the percent of E-RFC and absolute number of T-lymphocytes. In some patients, normalization of the PHA response and delayed skin test was observed, whereas in other subjects the same parameters remained unvaried. Part of the results reported here were similar to those mentioned previously. 
Clinical improvement was evident in four patients of eight with T-cell defects, as shown by the healing of mucosal and skin infections, by disappearance of candidiasis, and all other infections.

Good correlation was observed between in vitro and in vivo tests in 11 of 13 patients. In six patients, results were positive and in five, negative. In two patients, there was no correlation, despite positive response in vitro, no modification was revealed in vivo by TS treatment.

In addition, the clinical benefit correlates less than immunologic assays, because, in two patients, despite immunologic improvements, the clinical condition worsened.

In the children who showed good clinical improvement, weight gain and normal intestinal function have now persisted for 2 years. In other patients with $\mathbf{T}$-cell defects or other immunodeficiencies, the benefit of TS therapy was only transitory or absent. In the four patients who showed clinical improvement, there was a reconstitution of cellular immunity which has now lasted for more than a year, whereas in other patients, this reconstitution has been only temporary or absent.

It is of interest to note that the length of TS therapy may be of importance in determining a positive response. In fact, in one patient deprived of this therapy for 2 weeks after the initial 1 week of treatment, albeit for reasons beyond our control, (i.e., lack of available TS for a limited period of time), the improvement of clinical and immunologic parameters was followed by a relapse. Only with a further course of normal duration, long-term improve-

Table 4. B-lymphocytes and serum immunoglobulins in patients with T-lymphocytes defect before and after TS therapy

\begin{tabular}{|c|c|c|c|c|c|}
\hline \multirow[b]{2}{*}{ Patient } & \multirow[b]{2}{*}{ Test $^{2}$} & \multirow[b]{2}{*}{ Before } & \multicolumn{3}{|c|}{ After $^{1}$} \\
\hline & & & 1 & 12 & $24-56$ \\
\hline \multirow[t]{3}{*}{ 1. R. R. } & IG & $\mathrm{N}^{3}$ & $\mathrm{~N}^{3}$ & $\mathrm{~N}^{3}$ & $\mathrm{~N}^{3}$ \\
\hline & B \% & 8 & 16 & $\mathrm{ND}^{4}$ & 17 \\
\hline & $\mathrm{B} / \mathrm{mm}^{3}$ & 76 & 67 & $\mathrm{ND}^{4}$ & 510 \\
\hline \multirow[t]{3}{*}{ 2. C. A. } & Ig & $\mathrm{N}^{3}$ & $\mathrm{~N}^{3}$ & $\mathrm{ND}^{4}$ & $\mathrm{~N}^{3}$ \\
\hline & B \% & 15 & 26 & $\mathrm{ND}^{4}$ & 30 \\
\hline & $\mathrm{B} / \mathrm{mm}^{3}$ & 23 & 138 & $\mathrm{ND}^{4}$ & 300 \\
\hline \multirow[t]{3}{*}{ 3. L. M. } & Ig & $\mathrm{N}^{3}$ & $\mathrm{~N}^{3}$ & $\mathrm{~N}^{3}$ & $\mathrm{ND}^{4}$ \\
\hline & B \% & 4 & 7 & 8 & $\mathrm{ND}^{4}$ \\
\hline & $\mathrm{B} / \mathrm{mm}^{3}$ & 48 & 182 & 320 & $\mathrm{ND}^{4}$ \\
\hline \multirow[t]{3}{*}{ 4. C. C. } & Ig & $\mathrm{N}^{3}$ & $\mathrm{~N}^{3}$ & $\mathbf{N}^{3}$ & . $\mathbf{N}^{3}$ \\
\hline & B \% & 13 & 7 & 13 & 13 \\
\hline & $\mathrm{B} / \mathrm{mm}^{3}$ & 234 & 280 & 663 & 689 \\
\hline \multirow[t]{3}{*}{ 5. A. A. } & $\mathrm{Ig}$ & $\mathrm{N}^{3}$ & $\mathbf{N}^{3}$ & $\mathrm{~N}^{3}$ & $\mathrm{~N}^{3}$ \\
\hline & B \% & $\mathrm{ND}^{4}$ & $\mathrm{ND}^{4}$ & $\mathrm{ND}^{4}$ & $\mathrm{ND}^{4}$ \\
\hline & $\mathrm{B} / \mathrm{mm}^{3}$ & $\mathrm{ND}^{4}$ & $\mathrm{ND}^{4}$ & $\mathrm{ND}^{4}$ & $\mathrm{ND}^{4}$ \\
\hline \multirow[t]{3}{*}{ 6. M. G. } & Ig & $\mathrm{N}^{3}$ & $\mathrm{~N}^{3}$ & $\mathrm{~N}^{3}$ & \\
\hline & B \% & 13 & 3 & $\mathrm{ND}^{4}$ & \\
\hline & $\mathrm{B} / \mathrm{mm}^{3}$ & 338 & 60 & $\mathrm{ND}^{4}$ & \\
\hline \multirow[t]{3}{*}{ 7. F. D. } & $\mathrm{Ig}$ & $\mathrm{N}^{3}$ & $\mathbf{N}^{3}$ & $\mathrm{~N}^{3}$ & $\mathrm{~N}^{3}$ \\
\hline & B \% & 9 & 21 & 8 & 4 \\
\hline & $\mathrm{B} / \mathrm{mm}^{3}$ & 180 & 525 & 280 & 200 \\
\hline \multirow[t]{3}{*}{ 8. P. G. } & Ig & $\uparrow^{5}$ & $\uparrow^{5}$ & $\uparrow^{5}$ & \\
\hline & B \% & 22 & 25 & 28 & 21 \\
\hline & $\mathrm{B} / \mathrm{mm}^{3}$ & 114 & 148 & 154 & 322 \\
\hline
\end{tabular}

\footnotetext{
'Weeks after TS therapy.

${ }^{2}$ B: lymphocytes with surface binding IG.

${ }^{3} \mathrm{~N}$ : values within normal range.

${ }^{4} \mathrm{ND}$ : not done.

${ }^{5} \uparrow:$ increased values.
}

ment ensued. While it is difficult to draw precise and definitive conclusions from only one case, this patient seems to suggest that a minimum course of therapy may be a necessary requirement for long-term positive results.

These results can be explained in various ways: 1) The permanence of the reconstitution could be due to the maturation of a long lived immunocompetent cell population which recirculates. 2) In patients with $T$-cell depression, which may be primary or worsened by the infectious stress, TS therapy could help to eliminate one of the causes of T-cell dysfunction. Similar findings were recently obtained by Varsano et al. (18). 3) In our cases, a mechanism similar to that proposed by Ammann et al. (3) with fetal thymus transplant might affect the long lasting reconstitution. These authors suggest that humoral thymic factor produced by the transplanted thymus can stimulate residual stromal thymic cells of the host which by themselves are not capable of inducing immunocompetence. Unfortunately, in our patients, thymic hormone(s) levels were not examined before and after therapy. The therapeutic benefit observed in patients with $T$-lymphocyte defects can be explained by the fact that this immunodeficiency is probably caused by a thymic hormone defect. These data found support in the recent findings of Goldstein et al. (10) who have demonstrated an absence of circulating thymic hormone activity in patients with T-cell defect.

On the contrary, in patients with T-cell defect who did not show benefit, several hypotheses could be put forward: 1) An absence of the stem cells rather than a defect of cell differentiation could be postulated. However, this fact is contrary to the positive response in vitro. Instead of an absence of stem cells, a partial defect can be presumed. 2) TS may not be capable of correcting the immunologic defect when there is an absence of other circulating thymic factors with different chemical, physical, and functional characteristics, or when the defect of T-cells is not attributable to a lack of thymic hormones. However, this hypothesis also is against our in vitro studies. 3) The doses of TS used may not have been sufficient for the critical conditions of some patients with a severe lack of thymic function. Moreover, the severe toxic condition caused by the infections could have negatively influenced the efficacy of TS therapy.

In the patients with W-A syndrome, a reconstitution of cellular immunity and improvement in the clinical symptoms were seen. Nevertheless, these findings do not permit us to conclude that a lack of thymic hormones is one of the causes of the immunologic deficiency in this syndrome. The absence of stem cells in patients with SCID explains the negative results obtained in vivo in agreement with the in vitro studies.

The absence of any effect in CVA patients with associated Tdefect also seems to suggest that deficit of $T$-helper cells has no pathogenetic relation to the hypogammaglobulinemia.

In conclusion, thymic hormone therapy could be a valid aid only in certain pathologic conditions characterized by T-lymphocyte defects and severe viral, bacterial, or fungal infections. Further clinical research with this drug is necessary to establish the optimal therapeutic dose, duration of therapy in various forms of immunodeficiencies, mean life of TS, and to see whether the administration of thymic extracts may be extended to other forms of cellular immunodeficiency associated with lymphoproliferative, autoimmune, and neoplastic diseases.

\section{CONCLUSION}

Thymic humoral facter, denominated thymostimulin (TS), extracted from bovine calf thymuses, was demonstrated to have the capacity to restore the immunocompetence of immature T-cells of some patients with severe viral and fungal infections associated with a defect of thymus-dependent system.

In some infants, the clinical improvement correlates with in vivo and in vitro immunologic tests.

Patients with other forms of cellular immunodeficiencies and B-cell defects show neither clinical nor immunologic benefits.

The in vitro assay (E-rosette forming cells and acquisition of 
human T-lymphocyte antigen in presence of TS) is a useful test to predict whether patients with impairment of cell mediated immunity will respond or not to thymic extract therapy. Negative in vitro response to TS is definitely contrary to treatment of patients.

\section{REFERENCES AND NOTES}

I. Aiuti, F., Fiorilli, M., Ammirati, P., D’Amelio, R., and Businco, L.: Thymus transplantation and thymic hormone therapy in patients with T-cell deficiency. IV International Symposium, Japan Medical Research Foundation, p. 331 (University Tokyo Press, Tokyo 1978).

2. Aleksandrowcz, J., and Skotnicki, A. B.: The role of the thymus and thymic humoral factors in immunotherapy of aplastic and proliferative diseases of the hemopoietic system. Acta Med. Pol., 17: 1 (1976).

3. Ammann A. S., Wara, D. W., Doyle, N. E., and Golbus, M. S.: Thymus transplantation in patients with thymic hypoplasia and abnormal immunoglobulin synthesis. Transplantation, 20: 457 (1975).

4. Astaldi, A. and Astaldi, G.: Historical review of thymic hormones. Wadley Med. Bull., 5: 2 (1975).

5. Bach, J. F.: Thymic hormones. From myth to facts. Clin. Immunol. Immunopathol., 5: 171 (1976).

6. Falchetti, R., Bergesi, G., Fafiero, C., Eshkol, A., and Caprino, L.: Pharmacological and biological properties of a calf thymus extract (TP-7). Drugs Exptl. Clin. Res. 3: 39 (1977).

7. Fiorilli, M., Ammirati, P., Pandolfi, F., Sirianni, C., Aiuti, F.: Immunological and clinical investigation of a bovine thymic extract. I. In vitro effect on T-cell differentiation in normal and in pathological conditions. Annali Sclaro (in press).

8. Goldstein, A. L., Thurman, G. B., Cohen, G. H., and Hooper, J. A.: The role of thymosin and the endocrine thymus in the ontogenesis and function of T-cells. In: E. E. Smith and D. W. Robins Molecular approaches to immunology p. 243 (Miami Winter Symposia, Academic Press, N.Y. 1976).

9. Goldstein, A. L., Thurman, G. B., Cohen, G. H., and Hooper, J. A.: Thymosin chemistry, biology and clinical application. In: Biological activity of thymic hormones, p. 173 (Kookyer Scientific Publishers, Rotterdam, The Netherlands, 1975).

10. Goldstein, G., Smithvick, E., and Pahwa, S.: Circulating thymic-hormone activity in congenital immunodeficiency. Lancet, 2: 471 (1977).

11. Hobbs J.: Personal communication (1977)

12. Leikin, S., Mochir-Fatemi, F., and Park, K.: Blast transformation of lymphocytes from newborn human infants. J. Pediatr., 72: 510 (1968).

13. Mancini, G., Carbonara, A. O., and Heremans, J. F.: Immunochemical quantitation of antigen by single radial immunodiffusion. Immunochemistry, 2: 235 (1965).

14. Masuda, T., Idehara, S., and Hamashima, V.: Restoration of T-cell functions by a thymus factor in nude mice. Abstract of the symposium on "Immunodeficiency, its nature and etiological significance in human disease", Tokyo, Sept. 13-15 (1976).

15. Pernis, B., Forni, L., and Amante, L.: Immunoglobulin spots on the surface of rabbit lymphocytes. J. Exptl. Med., 132: 100 (1971).

16. Polmar, S.: ADA deficiency enzyme replacement therapy and investigation of biochemical basis of immunodeficiency. Proceedings of the III International Workshop of the International Cooperative Group for Bone Marrow Transplantation in Man. New York, Aug. 19-21, 1976 (abstract).

17. Turowski, G., Cybulski, L., Politowski, M., Turaszwill, T., and Zubel, M.: First trials of immunopotentiation by thymus extract (TFX) in surgical patients with malignant disease. Acta Med. Pol., 17: 1 (1976).

18. Varsano, I., Schonfeld, T. A., Matoth, V., Shohat, B., Englander, T., Rotter, V., and Trainin, N.: Severe disseminated adenovirus infection successfully treated with a thymic humoral factor, THF. Acta Paediatr. Scand., 66: 329 (1977).

19. Wara, D. M., Goldstein, A. L., Doyle, M. F., and Amman, J.: Thymosin activity in patients with cellular immunodeficiency, N. Engl. J. Med., 292: 70 (1975)

20. The authors thank the Serono Institute (Rome) for providing the thymic extract.

21. Requests for reprints should be addressed to: F. Aiuti, Department of Internal Medicine III, University of Rome, Rome (Italy).

22. Received for publication January $18,1978$.

23. Accepted for publication June 29, 1978. 